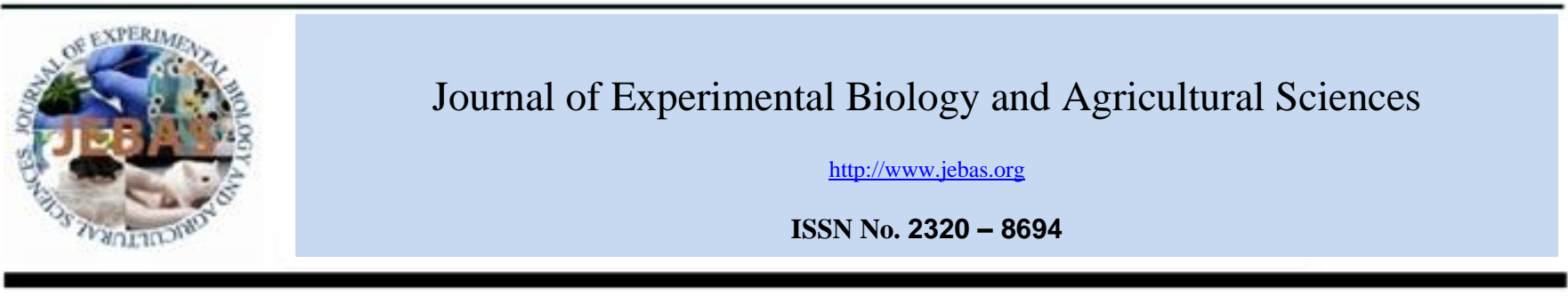

\title{
ANTIOXIDANT ACTIVITY OF VITAMIN E AND ITS ROLE IN AVIAN REPRODUCTION
}

\section{Vincenzo Tufarelli* and Vito Laudadio}

Department of Emergency and Organ Transplantation (DETO), Section of Veterinary Science and Animal Production, University of Study of Bari 'Aldo Moro', Valenzano 70010 Bari, Italy.

Received - April 18, 2016; Revision - April 25, 2016; Accepted - May 21, 2016

Available Online - May 25, 2016

DOI: http://dx.doi.org/10.18006/2016.4(3S).266.272

\section{KEYWORDS}

Vitamin E

Antioxidant

Reproduction

Avian Species

\begin{abstract}
Oxidative stress, a state characterized by imbalance between pro-oxidant molecules comprising reactive oxygen and nitrogen species, and antioxidant defences, has been found to play an important in poultry reproduction in both male and female Increasing evidence suggests that vitamin E plays an important role in normal reproduction in animals and humans, and vitamin $\mathrm{E}$ supplementation is now recommended. Vitamin E comprises eight molecules composed by a chromanol ring and a phytol side chain having same functions: four tocopherols $(\alpha, \beta, \gamma$, and $\delta)$ and four tocotrienols $(\alpha, \beta, \gamma$, and $\delta)$. This article reports an overview on the currently available literature on the role of reactive species and oxidative stress in avian reproductive processes. Current evidences demonstrate that dietary vitamin $\mathrm{E}$ supplementation may be effective in controlling the production of reactive oxygen species and continue to be explored as a potential feeding strategy to support avian reproduction.
\end{abstract}

* Corresponding author

E-mail: vincenzo.tufarelli@uniba.it (Vincenzo Tufarelli)

Peer review under responsibility of Journal of Experimental Biology and Agricultural Sciences.

Production and Hosting by Horizon Publisher India [HPI] (http://www.horizonpublisherindia.in/).

All rights reserved.
All the article published by Journal of Experimental Biology and Agricultural Sciences is licensed under a Creative Commons Attribution-NonCommercial 4.0 International License Based on a work at www.jebas.org.

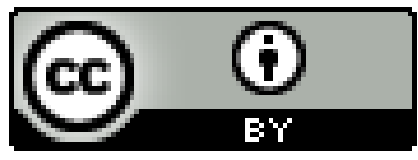




\section{Introduction}

In overall, poor fertility is mostly related to male bird, even though females may be rather responsible for the flock fertility decline (Hocking \& Bernard, 2000; Habibian et al., 2014). In addition, the strong genetic selection for large breast progeny, low frame size, reduction of libido, age, environment, feed and stress are some factors influencing fertility in poultry (RomeroSanchez et al., 2008; Khan et al., 2012). Therefore, the oxidative stress has been identified as one of the major factors affecting reproductive parameters and thus has been widely investigated in recent years.

Carotenoids and vitamins $\mathrm{A}, \mathrm{D}, \mathrm{E}$ and $\mathrm{K}$ are liposoluble compounds naturally present in food or feed used as excipients in industrial fields such as pharmaceutics. Nevertheless, carotenoids do not belong to the common vitamins classification and they are commonly studied with liposoluble vitamins as fifty carotenoids among the over 600 carotenoids identified to this day are pro-vitamin A elements (Gonnet et al., 2010; Jones et al., 2013). Vitamins are receptive compounds, they must be preserved from pro-oxidant elements which could influence their chemical integrity and decrease their physiological benefits.

Vitamin E includes eight molecules composed by a chromanol ring and a phytol side chain having same functions: four tocopherols $(\alpha, \beta, \gamma$, and $\delta)$ and four tocotrienols $(\alpha, \beta, \gamma$, and $\delta)$ (Górnaś, 2015). Tocopherols contain saturated side chain, while tocotrienols possess 3 conjugated double bonds. The $\alpha$, $\beta, \gamma$ and $\delta$ prefixes represent the methyl groups position on chromanol ring (Hincha, 2008). The $\alpha$-Tocopherol is the richest in nature and one $\alpha$-tocopherol molecule can catch two peroxyl radicals responsible of lipid oxidation start (Niki et al., 1984; Brigelius-Flohe \& Traber, 1999). Thus, $\alpha$-tocopherol molecule protects membrane lipids against oxidation (Niki et al., 1991), and it stabilizes mechanically the membranes (Srivastava et al., 1983). Vitamin E digestion is similar to vitamin $\mathrm{A}$ and carotenoids digestion. Vitamin $\mathrm{E}$ deficiency might occur in case of fat malabsorption being usually characterized by neurological problems due to poor nerve conduction, which are reversible by supplementation (Brigelius-Flohe \& Traber, 1999).

The $\alpha$-Tocopherol is a main constituent of vitamin $\mathrm{E}$ in the leaves of plants. It is a capable antioxidant and through numerous studies it has been shown to play a key-role in protecting the photosynthetic apparatus of plants against oxidative damage especially under stress conditions (MunneBosch, 2005). Vitamin E plays an important role in the transport of amino acids and probably lipids in the intestine (Wang \& Quinn, 2000). Vitamin E is also involved in iron metabolism and steroidogenesis (MacDonald et al., 1991), and it stimulates humoral and cellular immune responses against infectious diseases (Oliver et al., 1998). The symptoms and disorders of vitamin E deficiency vary, depending on the species affected (Baldi et al., 2013; Habibian et al., 2014).
Vitamin E deficiency may manifest itself in a number of disorders in organs and in adipose tissue (Matringe et al., 2008). Vitamin E deficiency may increase the risk of ischemic heart disease, breast cancer, and the incidence of infections (Hincha, 2003), and it promotes susceptibility to dietary and environmental stress in humans and animals (Oliver et al., 1998; Wang \& Quinn, 2000; Khan et al., 2011). Compared to findings in humans, available data from animal trials show that vitamin $\mathrm{E}$ toxicity is low and that the vitamin $\mathrm{E}$ results not mutagenic, carcinogenic, or teratogenic (Munne-Bosch, 2005).

Vitamin E has also a positive effect on fertility (Khan et al., 2012). In particular, the activity of vitamin $\mathrm{E}$ was first identified as an essential dietary factor for male and female reproduction in rats (Della Penna, 2005; Khan et al., 2011). Although vitamin $\mathrm{E}$ has a wide range of functions in the body, it is primarily crucial for fertility in humans and livestock species. In the poultry farming, males are added into flock of hens to produce fertile egg which dictate the final flock profitability (Ordas et al., 2015). For that reason, male fertility is essential in the net income of avian industry.

\section{Free radicals and oxygen and lipid peroxidation}

In biological systems, the reactive oxygen species (ROS) or also free radicals are produced by the prooxidative enzyme systems, irradiation lipid oxidation, air pollutants and glycoxidation (Halliwel, 1997; Sabry, 2013; Kostadinović et al., 2015). The generation of free radicals induced oxidative stress which associated with many degenerative diseases, including atherosclerosis, vasospasms, cancers, stroke, hyperoxia, arthritis, heart attack, age pigments, dermatitis, liver injury and induction of apoptosis (Simon et al., 2000; Niki, 2014; Rahal et al., 2014). In animals, free radicals are also associated with metabolic disorders, diabetes and infectious diseases. In the contrary there are some benefits of free radicals have been reported. These benefits are the activation of nuclear transcription factors, gene expression and destructive effect to tumor cells and microorganisms (Packer \& Weber, 2001). Superoxide radicals $(\mathrm{O} \bullet-2)$ act as controller for the growth of cells (Bhattacharyya et al., 2014); in addition, it can assault a lot of pathogens stimulating inflammatory responses (Stief, 2003). Nitric oxide (NO•) is signaling molecules participating in cellular and organ function as a neurotransmitter and a mediator of the immune responses (Fang et al., 2002).

In living organisms under aerobic conditions more than $90 \%$ of oxygen consumed is reduced directly to water by cytochrome oxidase in electron-transport chain via four-electron mechanisms without ROS release (Lushchak, 2014).

Oxidative stress is caused by the imbalance between prooxidants and antioxidants at either cellular or individual level (Panda \& Cherian, 2014; Rahal et al., 2014). The production of ROS, also defined as oxidants, has become a concern because of their potential toxic consequence, at higher levels, on semen quality and functions (Agarwal et al., 2003; Khan et al., 2012). 
Also, ROS are highly reactive agents belonging to the class of free radicals. All living cells including spermatozoa regularly face the oxygen paradox. The oxygen is necessary for maintaining life; nevertheless, its metabolites, such as ROS, must be neutralized constantly to support the small amount essential for physiological cell function (Niki, 2014; Surai, 2016). The spermatozoa PUFAs are extremely susceptible to lipid peroxidation, as a result, ROS are produced in high quantity, which are harmful to the fertilizing capability of semen (Agarwal et al., 2003). Due to an increased production of ROS, oxidative stress, which is the imbalance between prooxidants and antioxidants happens (Agarwal et al., 2003; Urso \& Clarkson, 2003; Surai, 2016).

Under normal conditions, the body generally has enough reserves of antioxidants to manage with the ROS production (Castillo et al., 2001). Nevertheless, in particular conditions of stress when ROS production exceeds the body's antioxidant capacity, oxidative stress occurs. The oxidative stress determines a reduction of sperm quantity, decreasing also spermatozoa motility and increasing the dead sperm (Sikka, 2001; Agarwal et al., 2003; Khan et al., 2012), determining reproductive problems.

The lipid peroxidation can be described in overall as a process where the oxidant compounds (i.e. free radicals or non-radical species) assault lipids with carbon-carbon double bond, in particular PUFAs involving hydrogen abstraction from a carbon (Yin et al., 2011; Ayala et al., 2014). In reply to peroxidation of the lipid membrane, and along with specific cellular metabolic circumstances and restore capacity, the cell can support cell survival or stimulate cell death (Ayala et al., 2014).

The impact of lipid oxidation in cells and how damages are implicated in physiological processes and pathological conditions have been investigated in previous studies (Yin et al., 2011; Volinsky \& Kinnunen, 2013; Ayala et al., 2014). In modern poultry production is associated with various stress conditions that are responsible of a decrease in productive and reproductive traits of young poultry, breeders and layers (Celi et al., 2014; Surai, 2016).

One of the very significant sources of lipid peroxidation is mitochondria, which having a key-role in ROS production through the NADH-dependent oxido-reductase system (Hallak et al., 2001). Mitochondria are present in adequate levels in gametes providing mechanical energy for motility. The inner mitochondrial membrane potential is very important in regulating sperm functions. Wang et al. (2003) reported that mitochondrial membrane potential decreased in spermatozoa of infertile subjects with high levels of ROS production and have a significant correlation with concentration of sperm. High ROS level disrupts the outer and inner mitochondrial membrane determining the release of cytochrome $\mathrm{C}$ protein and activate caspases to stimulate apoptosis (Khan et al., 2012).
The damage of DNA and cross linking proteins can in addition decline the quality of semen (Sharma \& Agarwal, 1996). The exposure of sperm to artificially produced ROS determines the damage in form of modification of all bases, frame shifts and DNA cross-links (Duru et al., 2000). Spermatozoa with dysfunctional DNA are unable to fertilize the oocyte, and thus, fertilisation rate decreases with increasing DNA damage (Sun et al., 1997; Khan et al., 2012).

\section{Dietary vitamin $E$ on reproduction activity in avian species}

Available published review papers report that dietary vitamin E supplementation of a balanced poultry ration significantly supports reproductive functions, including semen volume, sperm concentration, sperm viability, sperm motility, and sperm capacity, in avian species (Khan et al., 2012; Rakha et al., 2015; Rengaraj \& Hong, 2015). The vitamin E is getting substantial interest in poultry feeding due to its key- role as a dietary antioxidant to prevent oxidative stress (Dhama et al., 2014). Vitamin E is a well-documented fat-soluble antioxidant and has been shown to inhibit free radical-induced damage to sensitive cell membranes (Panda \& Cherian, 2014; Rengaraj \& Hong, 2015). Vitamin E is supplemented to the diet to maintain and enhance performance in layers, broilers, broiler breeders, and turkey (Sunder et al., 1997; Panda et al., 2009; Khan et al., 2012). The results obtained varied depending upon the level and duration of feeding diets supplemented with vitamin E, genetic stocks, age, assessment criteria and stress conditions (Panda et al., 2009; Panda \& Cherian, 2014).

Vitamin $\mathrm{E}$ is found in turkey semen, with a higher concentrations within sperm cells than seminal plasma (Surai, 1981). Moreover, it is a natural stabilizer of sperm plasma and membranes of mitochondrion (Surai \& Ionov, 1992) and it has been demonstrate to boost sperm mobility and viability during storage (Donoghue \& Donoghue, 1997).

Comparatively, lower vitamin E levels are present in both chicken and drake semen than in turkey, with significant low vitamin E found in gander (Surai \& Ionov, 1992). Furthermore, this vitamin is splitted between seminal plasma and spermatozoa, with higher amount in sperm cells of turkey than in seminal plasma as reported by Surai (1981). Even though observed in semen, supplementation of this vitamin in semen extenders produced conflicting findings in reducing peroxidation. It was assessed that neither 10 nor $40 \mu \mathrm{g}$ of vitamin $\mathrm{E}$ was adequate to limit peroxidation under aerobic storage condition (Long \& Kramer, 2003). Additionally, the effect of vitamin $\mathrm{E}$ on the mobility and viability of sperm is somewhat contradictory. In fact, in a study on semen from turkeys, the supplementation of vitamin $\mathrm{E}$ increased sperm mobility as well as the membrane integrity (Donoghue \& Donoghue, 1997), whereas it was demonstrated no influence on mobility or viability when supplementing vitamin E (Long \& Kramer, 2003). Studies on mammalian species demonstrated an opposite relationship between lipid peroxidation degree and sperm mobility with vitamin $\mathrm{E}$. 
To improve poultry male reproductive traits, supplementing vitamin $\mathrm{E}$ in diet is used regularly in avian production. The dietary increase in the vitamin $\mathrm{E}$ inside semen was demonstrated to determine a significant decrease in the lipid peroxidation susceptibility (Niki, 1991; Lin et al., 2005). Moreover, Biswas et al. (2007) also reported that fertility was low in absence of vitamin $\mathrm{E}$ in a basal diet and when vitamin $\mathrm{E}$ was supplied, fertility was restored in birds.

Cerolini et al. (2006) reported that sperm levels were enhanced in male breeders by adding vitamin $\mathrm{E}$ at $200 \mathrm{mg} / \mathrm{kg}$ of diet. In addition, Biswas et al. (2009) found that including vitamin $\mathrm{E}$ in diet of cockerels significantly decreased the abnormal and dead spermatozoa proportion improving the birds fertility. The age decreases the fertility in cockerels and it was also linked with low levels of vitamin $\mathrm{E}$ in testes and this can be reinstated supplementing vitamin E (Surai et al., 2000). Lately, Ebeid (2014) demonstrated in male chicken that vitamin $\mathrm{E}$ in diet in combination with organic selenium has a synergistic influence in reducing lipid peroxidation and enhancing the antioxidative status in plasma of domestic fowl, which almost certainly translated into improved spermatozoa count, motility and decreased dead spermatozoa percentage under heat stress conditions.

In addition, Ipek \& Dikmen (2014) found that a dietary combination of vitamin E may affect significantly sexual maturity, egg mass and hatching traits of quails reared under heat stress. Increased dietary vitamin $\mathrm{E}$ supplementation of the maternal diet was associated with increased vitamin $\mathrm{E}$ concentrations in the egg yolk, embryonic tissues and their increased resistance to oxidative stress (Surai et al., 2016). In addition, Urso et al. (2015) reported that hatchability of the eggs of breeders fed $120 \mathrm{mg}$ vitamin E/ $\mathrm{kg}$ feed was higher than those fed diet containing $30 \mathrm{mg}$ vitamin $\mathrm{E} / \mathrm{kg}$ of feed.

\section{Conclusion}

The present literature review shows that vitamin $\mathrm{E}$ is required for the development and function of the reproductive tissues in both sexes, possibly due to its key role in the modulation of antioxidant balance. Biological systems are under a continuous influence of oxidative stress because of excessive generation of ROS. Although biological systems are affected in different ways by oxidative stress, there are sufficient antioxidant protections that can decrease the progression of the damage. Excessive ROS production and resulting OS may contribute to aging and several diseased states affecting reproduction. However, when an imbalance exists between levels of ROS and the natural antioxidant defenses, various measures can be used to protect humans against the oxidative stress -induced injury. Diet forms an important component of the antioxidant protection system; it supplies the major antioxidants such as vitamin $\mathrm{E}$. Thus, vitamin $\mathrm{E}$ is a crucial element due to its function in sustaining poultry well-being and reproductive success.

\section{Conflict of interest}

Authors would hereby like to declare that there is no conflict of interests that could possibly arise.

\section{References}

Agarwal A, Saleh RA, Bedaiwy MA (2003) Role of reactive oxygen species in the pathophysiology of human reproduction. Fertility and Sterility 79: 829-843. DOI: http://dx.doi.org/10.1016/S0015-0282(02)04948-8.

Ayala A, Muñoz MF, Argüelles S (2014) Lipid peroxidation: production, metabolism, and signaling mechanisms of malondialdehyde and 4-hydroxy-2-nonenal. Oxidative Medicine And Cellular Longevity, Article ID 360438, DOI: $10.1155 / 2014 / 360438$

Baldi S, Innocenti M, Frascerra S, Nannipieri M, Lippi A, Rindi P, Ferrannini E (2013) Effects of hemodialysis and vitamin $\mathrm{E}$ supplementation on low-density lipoprotein oxidizability in end-stage renal failure. Journal of Nephrology 26: 549-555. doi: 10.5301/jn.5000190.

Bhattacharyya A, Chattopadhyay R, Mitra S, Crowe SE (2014) Oxidative stress: an essential factor in the pathogenesis of gastrointestinal mucosal diseases. Physiological Reviews 94: 329-354. doi: 10.1152/physrev.00040.2012.

Biswas A, Mohan J, Sastry KV, Tyagi JS (2007) Effect of dietary vitamin $\mathrm{E}$ on the cloacal gland, foam and semen characteristics of male Japanese quail. Theriogenology 67: 259-263.

Biswas A, Mohan J, Sastry KV (2009) Effect of higher dietary vitamin $\mathrm{E}$ concentrations on physical and biochemical characteristics of semen in Kadaknath cockerels. British Poultry Science 50: 733-738. 35.

Brigelius-Flohe R, Traber MG (1999) Vitamin E: function and metabolism. FASEB Journal 13: 1145-1155.

Castillo C, Benedito JL, López-Alonso M, Miranda M, Hernández J (2001) Importancia del estrés oxidativo en ganado vacuno: en relación con el estado fisiológico (preñez y parto) y la nutrición. Archivos de Medicina Veterinaria 33: 5-20. http://dx.doi.org/10.4067/S0301-732X2001000100001.

Celi P, Selle PH, Cowieson AJ (2014) Effects of organic selenium supplementation on growth performance, nutrient utilisation, oxidative stress and selenium tissue concentrations in broiler chickens. Animal Production Science 54: 966-971.

Cerolini S, Zaniboni L, Maldjian A, Gliozzi T (2006) Effect of docosahexaenoic acid and $\alpha$-tocopherol enrichment in chicken sperm on semen quality, sperm lipid composition and susceptibility to peroxidation. Theriogenology 66:877-886. DOI: http://dx.doi.org/10.1016/j.theriogenology.2006.02.022. 
Della Penna D (2005) Progress in the dissection and manipulation of vitamin E synthesis. Trends in Plant Science 10: 574-579. DOI: http://dx.doi.org/10.1016/j.tplants.2005.10.007.

Dhama K, Tiwari R, Khan RU, Chakraborty S, Gopi M, Karthik K, Saminathan M, Desingu PA, Sunkara LT (2014) Growth promoters and novel feed additives improving poultry production and health, bioactive principles and beneficial applications: The trends and advances- A Review. International Journal of Pharmacology 10: 129-159. DOI: 10.3923/ijp.2014.129.159.

Donoghue AM., Donoghue DJ (1997) Effects of water-and lipid-soluble antioxidants on turkey sperm viability, membrane integrity, and motility during liquid storage. Poultry Science 76: $1440-1445$.

Duru NK, Moreshedi M, Oehninger S (2000) Effect of hydrogen peroxide on DNA and plasma membrane integrity of human spermatozoa. Fertility and Sterility 74: 1200-1207. DOI: http://dx.doi.org/10.1016/S0015-0282(00)01591-0.

Ebeid TA (2012) Vitamin E and organic selenium enhances the antioxidative status and quality of chicken semen under high ambient temperature. British Poultry Science 53: 708-714. doi: 10.1080/00071668.2012.722192.

Fang YZ, Yang S, Wu GY (2002) Free radicals, antioxidant and nutrition. Nutrition 18: 872-879. DOI: http://dx.doi.org/10.1016/S0899-9007(02)00916-4.

Gonnet M, Lethuaut L, Boury F (2010) New trends in encapsulation of liposoluble vitamins. Journal of Controlled Release 146: 276-290. doi: 10.1016/j.jconrel.2010.01.037.

Górnaś P (2015). Unique variability of tocopherol composition in various seed oils recovered from by-products of apple industry: rapid and simple determination of all four homologues ( $\alpha, \beta, \gamma$ and $\delta$ ) by RP-HPLC/FLD. Food Chemistry 172: 129-134. doi: 10.1016/j.foodchem.2014.09.051.

Habibian M, Ghazi S, Moeini MM, Abdolmohammadi A (2014) Effects of dietary selenium and vitamin E on immune response and biological blood parameters of broilers reared under thermoneutral or heat stress conditions. International Journal of Biometeorology 58: 741-752. doi: 10.1007/s00484013-0654-y.

Hallak J, Sharma PK, Pasqualotto FF, Ranganathan JR AJ, Thomas B, Agarwal A (2001) Creatine kinase as an indicator of sperm quality and maturity in men with oligospermia. Journal of Urology 58: 446-451. DOI: http://dx.doi.org/10.1016/S0090-4295(01)01224-9.
Halliwell B (1997) Antioxidants and human diseases: A general introduction. Nutrition Reviews 55: 44-49. doi: 10.1016/j.cca.2014.06.004.

Hincha DK (2008) Effects of $\alpha$-tocopherol (vitamin E) on the stability and lipid dynamics of model membranes mimicking the lipid composition of plant chloroplast membranes. FEBS Letters 582: 3687-3692. doi: 10.1016/j.febslet.2008.10.002.

Hincha DK (2003) Effects of calcium-induced aggregation on the physical stability of liposomes containing plant glycolipids. Biochimica et Biophysica Acta 1611: 180-186. doi:10.1016/S0005-2736(03)00053-1.

Hocking PM, Bernard R (2000) Effects of the age of male and female broiler breeders on sexual behaviour, fertility and hatchability of eggs. British Poultry Science 41: 370-376. DOI: $10.1080 / 713654925$.

Ipek A, Dikmen BY (2014) The effects of vitamin E and vitamin $\mathrm{C}$ on sexual maturity body weight and hatching characteristics of Japanese quails (Coturnix coturnix japonica) reared under heat stress. Animal Science Papers and Reports 32: 261-268.

Jones AMP, Baker R, Ragone D, Murch SJ (2013) Identification of pro-vitamin A carotenoid-rich cultivars of breadfruit (Artocarpus, Moraceae). Journal of Food Composition and Analysis, 31: 51-61.

Khan RU, Naz S, Nikousefat Z, Tufarelli V, Javdani M, Rana N, Laudadio V (2011) Effect of vitamin E in heat-stressed poultry. World's Poultry Science Journal 67: 469-478. DOI: http://dx.doi.org/10.1017/S0043933911000511.

Khan RU, Rahman ZU, Nikousefat Z, Javdani M, Laudadio V, Tufarelli V (2012) Vitamin E: pharmaceutical role in poultry male fecundity. World's Poultry Science Journal 68: 63-70. DOI: http://dx.doi.org/10.1017/S0043933912000074.

Kostadinović L, Lević J, Popović S, Čabarkapa I, Puvača N, Đuragić O, Kormanjoš Š (2015) Dietary inclusion of Artemisia absinthium for management of growth performance, antioxidative status and quality of poultry meat. European Poultry Science 79: 1-10. DOI: 10.1399/eps.2015.75.

Lin YF, Tsai HL, Lee YC, Chang SJ (2005) Maternal vitamin E supplementation affects the antioxidant capability and oxidative status of hatching chicks. The Journal of Nutrition 135: 2457-2461.

Long JA, Kramer M (2003) Effect of vitamin E on lipid peroxidation and fertility after artificial insemination with liquid-stored turkey semen. Poultry Science 82: 1802-1807. 
Lushchak VI (2014) Free radicals, reactive oxygen species, oxidative stress and its classification. Chemico-Biological Interactions 224: 164-175.

MacDonald RC, MacDonald RI, Menco BPM, Takeshita K, Subbarao NK, Hu L (1991) Small-volume extrusion apparatus for preparation of large, unilamellar vesicles. Biochimica et Biophysica Acta 1061: 297-303.

Matringe M, Ksas B, Rey P, Havaux M (2008) Tocotrienols, the unsaturated forms of vitamin $\mathrm{E}$, can function as antioxidants and lipid protectors in tobacco leaves. Plant Physiology 147: 764-778.

Munne-Bosch S (2005) The role of a-tocopherol in plant stress tolerance. Journal of Plant Physiology 162: 743-748.

Niki E, Saito T, Kawakami A, Kamiya Y (1984) Inhibition of oxidation of methyl linoleate in solution by vitamin $\mathrm{E}$ and vitamin C. Journal of Biological Chemistry 259: 4177-4182.

Niki E, Yamamoto Y, Komuro E, Sato K (1991) Membrane damage due to lipid oxidation. American Journal of Clinical Nutrition 53(Suppl 1): 201S-205S.

Niki E (2014) Role of vitamin E as a lipid-soluble peroxyl radical scavenger: in vitro and in vivo evidence. Free Radical Biology and Medicine 66: 3-12.

Oliver AE, Hincha DK, Crowe LM, Crowe JH (1998) Interactions of arbutin with dry and hydrated bilayers. Biochimica et Biophysica Acta 1370: 87-97.

Ordas B, Vahedi S, Seidavi A, Rahati M, Laudadio V, Tufarelli V (2015) Effect of Testosterone Administration and Spiking on Reproductive Success of Broiler Breeder Flocks. Reproduction in Domestic Animals 50: 820-825.

Packer L, Weber SU (2001) The Role of Vitamin E in the Emerging Field of Nutraceuticals. In: Nutraceuticals in Health and Disease Prevention, Kramer, K., P.P. Hoppe and L. Packer (Eds.). Marcel Dekker, New York, pp: 27-43.

Panda AK, Cherian G (2014) Role of vitamin E in counteracting oxidative stress in poultry. Journal of Poultry Science 51: 109-117.

Panda AK, Rama Rao SV, Raju MVLN, Shyam Sunder G, Reddy MR (2009) Effect of higher concentration of vitamin E supplementation on growth performance, immune competence and antioxidant status in broilers. Indian Journal of Poultry Science 44: 187-190.

Rahal A, Kumar A, Singh V, Yadav B, Tiwari R, Chakraborty S, Dhama K (2014) Oxidative stress, prooxidants and antioxidants: the interplay. BioMed Research International. Volume 2014, Article ID 761264, 19 pages. http://dx.doi.org/10.1155/2014/761264.
Rakha BA, Ansari MS, Hussain I, Malik MF, Akhter S, Blesbois E (2015) Semen characteristics of the Indian Red Jungle Fowl (Gallus gallus murghi). European Journal of Wildlife Research 61: 379-386.

Rengaraj D, Hong YH (2015) Effects of Dietary Vitamin E on Fertility Functions in Poultry Species. International Journal of Molecular Sciences 16: 9910-9921.

Romero-Sanchez H, Plumstead PW, Leksrisompong N, Brannan KE, Brake J (2008) Feeding broiler breeder males. 4. Deficient feed allocation reduces fertility and broiler progeny body weight. Poultry Science 87: 805-811.

Sabry M El-Bahr (2013) Biochemistry of Free Radicals and Oxidative Stress. Science International 1: 111-117

Sharma, RK, Agarwal A (1996) Role of reactive oxygen species in male infertility. Journal of Urology 48: 835-850.

Sikka SC (2001) Relative impact of oxidative stress on male reproductive function. Current Medicinal Chemistry 8: 851862.

Simon HU, Haj-Yehia A, Levi-Schaffer F (2000) Role of Reactive Oxygen Species (ROS) in the apoptosis induction. Apoptosis 5: 415-418

Srivastava S, Phadke RS, Govil G, Rao CNR (1983) Fluidity, permeability and antioxidant behaviour of model membranes incorporated with (alpha)-tocopherol and vitamin $\mathrm{E}$ acetate. BBA - Biomembranes 734: 353-362.

Stief TW (2003) The physiology and pharmacology of singlet oxygen. Medical Hypotheses, 60: 567-572

Sun JG, Jurisicova A, Casper RF (1997) Detection of deoxyribonucleic acid fragmentation in human sperm: correlation with fertilisation in vitro. Biology of Reproduction 56: 602-607.

Sunder A, Richter G, Flachowsky G (1997) Influence of different concentrations of vitamin $\mathrm{E}$ in the feed of laying hens on the vitamin E transfer to eggs. Proceedings of the Society for Nutritional Physiology 6: 14-152.

Surai PF (1981) Fat-soluble vitamins in turkey sperm. In: Proceedings of the 2nd Conference of Young Scientists, Zagorsk, USSR, pp. 55-56.

Surai PF (2016) Antioxidant Systems in Poultry Biology: Superoxide Dismutase. Animal Nutrition 1: 8.

Surai PF, Ionov I (1992) Vitamin E in goose reproduction. In Proceedings of the 9th International Symposium on Waterfowl, Pisa, Italy, pp. 16-18. 
Antioxidant activity of vitamin e and its role in avian reproduction

Surai PF, Fisinin VI, Karadas F (2016) Antioxidant Systems in Chick Embryo Development. Part 1. Vitamin E, Carotenoids and Selenium. Animal Nutrition, DOI:10.1016/j.aninu.2016.01.001.

Surai PF, Brillard JP, Speake BK, Blesbois E, Seigneurin F, Sparks NH (2000) Phospholipids fatty acid composition, vitamin $\mathrm{E}$ content and susceptibility to lipid peroxidation of duck spermatozoa. Theriogenology 53: 1025-1039.

Urso UR, Dahlke F, Maiorka A, Bueno IJ, Schneider AF, Surek D, et al. (2015) Vitamin E and selenium in broiler breeder diets: effect on live performance, hatching process, and chick quality. Poultry Science 94: 976-983.

Urso ML, Clarkson PM (2003) Oxidative stress, exercise, and antioxidant supplementation. Toxicology 189: 41-54.
Volinsky R, Kinnunen PK (2013) Oxidized phosphatidylcholines in membrane-level cellular signaling: from biophysics to physiology and molecular pathology. FEBS Journal 280: 2806-2816.

Wang X, Quinn PJ (2000) The location and function of vitamin $\mathrm{E}$ in membranes (review). Molecular Membrane Biology 17: 143-158.

Wang X, Sharma RK, Gupta A, George V, Thomas AJ, Falcone $T$ (2003) Alterations in mitochondria membrane potential and oxidative stress in infertile men: a prospective observational study. Fertility and Sterility 80 : 844-850.

Yin H, Xu L, Porter NA (2011) Free radical lipid peroxidation: mechanisms and analysis. Chemical Reviews 111: 5944-5972. 